\title{
Architecture_MPS

Article

\section{A Few Steps Away yet Worlds Apart: A Closer Look at Changing Streetscapes in Abu Dhabi}

\author{
Abdellatif Qamhaieh \\ Department of Architecture, American University in Dubai; aqamhaieh@aud.edu \\ Guest Editor: Mohamed El Kaftangui, Abu Dhabi University, Dubai \\ How to Cite: Qamhaieh, A. 'A Few Steps Away yet Worlds Apart: A Closer Look at Changing \\ Streetscapes in Abu Dhabi.' Architecture_MPS 17, 1 (2020): 4. \\ DOI: https://doi.org/10.14324/111.444.amps.2020v17i1.004.
}

Submission date: 18 October 2018; Acceptance date: 3 April 2020; Publication date: 22 April 2020

\section{Peer review:}

This article has been peer reviewed through the journal's standard double blind peer-review, where both the reviewers and authors are anonymised during review.

\section{Copyright:}

(C) 2020, Abdellatif Qamhaieh. This is an open access article distributed under the terms of the Creative Commons Attribution License (CC BY) 4.0 https://creativecommons.org/licenses/by/4.0/, which permits unrestricted use, distribution and reproduction in any medium, provided the original author and source are credited $\bullet$ DOI: https://doi.org/10.14324/111.444.amps.2020v17i1.004.

\section{Open access:}

Architecture_MPS is a peer-reviewed open access journal.

\begin{abstract}
Abu Dhabi, the capital of the United Arab Emirates, continues to change at a rapid pace in response to city branding efforts. Significant investments in the city's urban infrastructure and its built environment are widespread, as Abu Dhabi attempts to compete on the world stage and lure in tourists, corporations, and investors alike. City planners have been busy updating the city's urban spaces and streetscapes. They have been transforming it into a sleek and modern contemporary Arab city with a 'high-end' feel which has been successful thus far. As a result, Abu Dhabi's name has become synonymous with luxury, and the city's overall quality, livability, and resilience have improved significantly. At the other end of the spectrum, the lower-income segments of the society appear to be missing from the urban planning effort. Some of the urban upgrading interventions might be unintentionally taking away some of the vibrant and diverse aspects of informal street life. This is especially true in some areas, where monotonous and sterile newer environments and streetscapes are replacing the older, informal environments, mostly inhabited by lower-income workers. This paper takes a closer look at some of these older spaces and streetscapes in Abu Dhabi. Through a case study, it attempts to shed some light on some of these vibrant areas, which could potentially vanish soon. It also attempts to highlight the energetic nature of these streetscapes and bring this to the attention of city planners. The paper argues that valuable lessons could be learned from these informal spaces and that these lessons could contribute positively to future planning efforts in the city.
\end{abstract}

Keywords: gulf urbanism; Abu Dhabi; public spaces; informality; city branding 


\section{Introduction}

The globalisation of cities through rebranding and infrastructure improvements has become a worldwide trend recently. While not necessarily a new phenomenon by itself, the rapid emergence of new economic hubs (or world cities) of a historically lesser reputation has been witnessed more clearly and is a testament to the success of certain prescribed ingredients. ${ }^{1}$ Signature architecture, infrastructure upgrades, and easing of economic regulations seem to be the keys to success, ${ }^{2}$ and a clear example of this can be seen in the rise of Dubai ${ }^{3}$ and similarly Abu Dhabi and Al Doha - all now well-known cities and destinations for job seekers and tourists alike.

As a result of these city rebranding efforts, and the inevitable changes in lifestyles and demographics, Abu Dhabi's urban fabric and architecture are also continuously changing. Signature developments are now abundant in the city, and its importance as a global high-end hub is well-established. Its status has been reinforced recently with the opening of the Louvre Abu Dhabi and is expected to grow as more museums, and high-calibre cultural venues are completed. ${ }^{4}$ Other notable upgrades are those taking place within the city's public spaces: Many older landscapes and urban fixtures are being rapidly changed and enhanced following contemporary designs, international standards and best practices. ${ }^{5}$

Meanwhile, and as is usually the case in similar globalising cities, the situation of migrant workers at the lower end of the economic and social ranking becomes even more precarious. Present, as a by-product of the demand for labour in the global city, these migrant labour forces are pushed to the fringes. ${ }^{6}$ They are regularly excluded from mainstream society- both legally and 'spatially.' In a city such as Abu Dhabi, these migrant workers are often invisible others. 5 The spaces they inhabit are often marginal, neglected, and informal. So, when their run-down appearances conflict with the image of the city, they are usually upgraded into shiny new spaces.

In this reflective paper, I discuss a small urban space in Abu Dhabi that represents the dynamics above. The area in question is one of many informal and forgotten urban spaces dotting the city. It is one that falls outside the world-city narrative but is partially a by-product of this narrative and a multitude of other context-specific factors. Low-income workers occupy the area, but it is a vibrant and lively space in contrast to some other more sterile upgraded parts of the city. The paper also sheds some light on the complex factors at play and shaping the built environment in Abu Dhabi. It reviews some of the literature covering various aspects that make the city unique. The paper advances the argument that although issues related to urban informality are common around the world, the case in Abu Dhabi is a bit different. The convergence of several unique elements makes the contrast within the city's adjacent but differing public spaces very visible. The paper contributes to the body of research surrounding urbanity in the Gulf Cooperation Council (GCC) region, and to the literature focused on marginalisation in globalising cities. It concludes by discussing lessons learned for planners with the hope of influencing local planning decisions.

\section{Pavements, Public Spaces and Street Life}

The importance of good urban design and its role in sustaining street life has been discussed extensively in the literature. From the work of Jane Jacobs ${ }^{7}$ to that of Kevin Lynch ${ }^{8}$ and others, most argue and agree that while design plays a significant role in sustaining street life, it is the context, ${ }^{9}$ the surrounding land uses, and the demographics that play a more prominent role. ${ }^{10}$ One of the critical ingredients for vibrant urban spaces is the presence of sufficient pavements and street-level commercial activity, as argued by Jacobs and others. Unfortunately, in most cities around the world, pavements are no longer viewed as public spaces but as merely pedestrian thoroughfares mirroring the thinking behind road design and transport planning. ${ }^{11}$ Some scholars argue that by strictly viewing pavements as pedestrian thoroughfares, transportation planners have managed to strip them of a lot of their vibrancy, especially in the US context. ${ }^{12}$ Since pavements usually fall within the jurisdiction of infrastructure for municipal engineers, a focus on efficiency in the execution and design of pavements supersedes the understanding of their essential role as enablers of urban vibrancy. Pavements are the actual public spaces of the cities: in these spaces, users engage with one another, provided that the conditions and context are conducive. ${ }^{13}$ 
On the other hand, poorly planned, disjointed, sterile pavements weaken the chances of casual social interaction and could even increase the likelihood of detrimental use of public space - such as criminal activity. As described by Jan Gehl, 'When outdoor areas are of poor quality, only strictly necessary activities occur. ${ }^{14}$

Pavements in Abu Dhabi, in general, have had little importance until recently. Although they have historically defined most boulevards and streets in the city, a closer look demonstrates how these were mostly planned and executed as an afterthought. The majority of these represent merely road edges or beautifications for passing car drivers. Pavements in Abu Dhabi are typically positioned in a grey area of responsibility for infrastructure agencies and are subject to the authority of these agencies. That is, they are not considered as a separate infrastructure form by themselves. Although this has started to change with the introduction of contemporary street design regulations, and with some upgraded pavements and infrastructure, ${ }^{15}$ still pavements remain an afterthought in most cases. They are often poorly executed, even in some of the newly developed or upgraded areas.

\section{The Dominance of Cars and the Shrinking Social Space}

Dependence on cars is plaguing urban areas worldwide. Large cities around the world are suffocating under the brunt of millions of vehicles, and their arteries continue to be clogged. In the United Arab Emirates (UAE), the situation is not much better: in a country with an extreme climate, car culture has had a strong foothold and long history ever since the county's independence. The UAE and the GCC cities generally have a very high per capita car ownership rate, due mainly to cheap gas prices and the hot and humid weather. ${ }^{16}$ It is common for some families in the region to own up to eight cars (or more). This automobile dominance is visible in the city, with its wide highway-like boulevards, multi-lane streets, higher than usual speed limits, and pedestrian underpasses or overpasses. Even more apparent is the issue of parking, which plagues the public spaces of the city by effectively eroding them. ${ }^{17}$ One of the main concerns for the city's residents is, 'where do I park my car?'. For the majority, a primary consideration when choosing accommodation in addition to affordability is parking availability. Many residents of Abu Dhabi prefer to live in distant suburbs where they can park multiple cars easily and freely on the sides of the streets, despite the long commute and shortages of services and amenities in these areas.

The dominance of cars in Abu Dhabi is no secret, while pedestrians and cyclists are considered of a much lower status. As a city that boomed in the 1970s, city blocks were designed to optimise traffic flow at the expense of pedestrians-friendly distances. Most residents assume and expect to be driven from point to point in the climate-controlled safety of their cars. Most public spaces in the city have long surrendered to the car culture, and have been transformed into car parks to address the never-ending parking shortage. Car drivers in Abu Dhabi expect to arrive at their destinations with minimal interaction with the outdoor 'icky' public space and its 'inferior' inhabitants. It is fair to say that the society is divided into two major categories: car owners and everyone else. This issue also has implications related to the mobility of these lower-income residents, as discussed by Qamhaieh and Chakravarty. ${ }^{18}$

\section{Flows of Labour and the Social Divide}

As cities continue to globalise, so does the workforce.6 In the GCC, the situation is even more noticeable. Historically, with high oil revenues, the need for foreign professional and blue-collar workers has been strong. The presence of such an international workforce is especially visible in countries with a small local population such as the UAE and Qatar. ${ }^{19}$ In Abu Dhabi, the majority of the population is an expatriate one. As of 2018, out of the city's nearly one million residents, roughly 200,000 were nationals, whereas the rest of the population reside in the city for economic reasons. ${ }^{20}$ As Abu Dhabi is becoming more of an international destination, the nature of this population is becoming more diverse, and more countries are represented. A large number of Western expatriates call Abu Dhabi home, which is something of a departure from the past when most expatriates were from Arab countries or from Southeast Asian countries.

Economically, the expatriate workforce in Abu Dhabi can be divided into two main categories: white-collar professionals with relatively moderate to high paying jobs, and blue-collar workers. 
The overwhelming majority of blue-collar workers are from nearby Arab countries and Southeast Asia, in which the Indian subcontinent is over-represented, and so is the Philippines. As the global status of the city continues to grow, the need for more labour of all levels also increases, and so does the polarisation of the society. This social polarisation is a common theme in the literature surrounding world cities, and now it is more evident in the limited research about GCC cities. ${ }^{21}$

\section{Informality in GCC Cities}

'Urban informality' is a term that describes events taking place outside of the formal state-regulated channels and is usually concerned with practices related to the accommodation arrangements, and the social and retail activities of disenfranchised or marginalised low-income populations. Roy ${ }^{22}$ describes informality in the urban setting in different forms. He indicates that most of these informalities take place in fringe areas, especially where rural and urban lifestyles and influences meet, or in dense old urban areas stricken by poverty and neglect. In all cases, he argues that informality, although treated as a separate unavoidable process by planners and city officials, is, in fact, a failure of the state in general and urban planning in particular. He further argues that it is an issue of social justice and rights to the city.

Although urban informality is widespread and very visible in the mega-cities of Southern Asia, it is also quite pronounced and prevalent in some Middle Eastern countries such as Egypt, Syria, Jordan and Yemen. ${ }^{23}$ The exception for this is the cities of the GCC countries, where it is camouflaged and remains limited in scale. Representations of informality are also usually suppressed in these cities through tightly controlled social and legal mechanisms, especially in those experiencing rapid upgrading processes, such as Abu Dhabi and Dubai.

In Dubai, for example, a city known for its spectacular attractions and glitzy shining towers, informality is not very obvious for the passing tourist or the casual observer. Still, it finds its way into some of the older areas of the city, where mostly lower-income families and labourers (often referred to as 'bachelors') reside. Yasser Elsheshtawy, a leading scholar on informality and urbanism in the GCC, documents such phenomena, and describes the ingredients and spatial characteristics necessary for them to emerge in this context. ${ }^{24} \mathrm{He}$ argues that the presence and concentration of low-income labourers and 'supportive settings' in certain areas cause these little spaces of urban vibrancy to emerge. Some of these supportive functions include eateries that provide ethnic foods, money exchange operations, and even unofficial telecommunication services. He goes further and describes these sites of informality as 'sites of exclusion,' where this disenfranchised population is allowed to exist until the areas are upgraded or the buildings demolished (similar to the case study of this paper). Elsheshtawy argues that these areas are cultural assets for the city, and should be treated as such by planners.

Another very well-known older area in Dubai where informal practices seem to thrive, and also a site of great controversy, was the Satwa neighborhood. In his work examining Satwa, Alawadi describes in detail the dynamics that led to its shaping and transformation, and the informal housing, trade, and even criminal, activities that were taking place in the neighbourhood. ${ }^{25}$ Despite the relative satisfaction of the residents, as argued by the author, the authorities decided to demolish the area. It was deemed unworthy because of its older urban fabric and low-income inhabitants. This 'urban violence,' as described by Alawadi, is a result of a top-down approach to planning, which favours business and large developers at the expense of the low-income segments of the society. At one point, it risked displacing 100,000 low-income families, only to be partially halted by the economic slowdown of 2008 .

There is less research available about urban informality in Abu Dhabi due mostly to the focus on neighboring Dubai and the more strict form of social control in the former. Elsheshtawy argues that planning in Abu Dhabi has been geared towards eliminating any type of informality ever since the city's inception $^{26}$. A well-known example was the old central market - a retail area in the centre of the city that was well known for its hustle and bustle, and chaotic appearance. It was an area deemed unworthy by city officials and was eventually replaced with a high-end residential and retail complex designed by Foster and Partners. Elsheshtawi further documents signs of informal urbanism throughout the city, including the areas for impromptu prayers, neglected spaces between buildings, and spaces unofficially borrowed or reclaimed for games of cricket or soccer. Nowadays, a large portion of older buildings in the city are 
being demolished, and the low-income residents (especially labourers) are forced into faraway industrial zones located at the urban fringes. Gentrification in Abu Dhabi is a rather ordinary and undisputed matter, considering the drive to globalise and the economic powers behind it.

More recently, the issue of urban informality in both Abu Dhabi and Dubai has become a contested topic, especially after the slowdown of projects and the realisation that top-down planning approaches do not always yield the best result. A drive to define and preserve urban heritage has also contributed to this debate. ${ }^{27}$

\section{Housing Shortages and the Inevitable Informal Solutions}

Housing in Abu Dhabi is a costly commodity. As an island city with limited available land, rental housing prices have been historically very high. Although nationals receive government loans and land subsidies, expatriates pay high rent, because they are excluded from ownership with the exception of some newer high-end areas such as Al-Reem Island. Most middle-class and above expatriates receive some form of housing allowance or compensation from employers as part of government-regulated work contracts.

At the lower end of economic standing, low-income workers have few options when it comes to housing. First, for those working in the construction industry, purpose-built worker villages are placed on the outskirts of the city. These worker cities are heavily regulated and provide a decent housing solution that would otherwise be impossible for those with minimal incomes. ${ }^{28}$ Although these worker villages have a fair share of amenities, they are often located on the outskirts of the city, far away from its centre. When labour is in demand for construction projects, the workers are transported in special buses to and from their accommodation.

For those workers employed by smaller establishments, there are few housing options. In some cases, companies rent an older apartment or a villa to provide their employees with housing. Although a common approach, it is often designed to serve mostly skilled workers with a somewhat higher than average income. Most other housing needs are handled by the informal market - an issue of great debate and contention in Abu Dhabi and the UAE in general. Older buildings in the city currently have filtered down and represent bed-space housing with little if any regulation. It is a much-needed service in which the informal market dominates, so it is not without problems. It is also subject to multiple crackdown initiatives by the municipal authorities because of the numerous health and safety violations associated with these arrangements. ${ }^{29}$ Certain older areas within the city are full of such accommodation. In the absence of any other viable solutions, the regulatory bodies are studying adopting these informal market solutions to resolve the housing crises for those with lower-incomes. The study of this paper is an example of such housing arrangements. ${ }^{30}$

\section{Case Study: Informality on Airport Road}

The informal urban space studied in this paper is located on the Old Airport Road, which is a major thoroughfare in Abu Dhabi. The specific space is directly adjacent to a relatively old neglected building, which is in poor condition overall (see Figure 1). The building is popular as a low-cost accommodation, similar to other buildings from around the same period in the city. Most of these period-defining buildings (built in the 1980s) are in a similar condition and go through the same filtering-down process until eventually demolished (with some rare exceptions where the building is preserved). The residents of such buildings are mostly low-income workers who rent bed spaces or share accommodation in different informal arrangements. The demographics of these workers change, usually depending on the area and the building's overall state. Still, the cheapest and most neglected buildings typically cater to male-only 'bachelor' accommodation. The building in question here is home to workers servicing nearby commercial facilities. On average, the cost of bed space in Abu Dhabi is between 500 and 750 AED. It is also a bed-space market that is highly segmented following nationality, religion, and gender (Figure 2). The case study area is not necessarily unique, with multiple examples around the city. Yet, this example stands out due to the rather car-dominated sterile surroundings in contrast to the vibrant public realm adjacent to the building. 


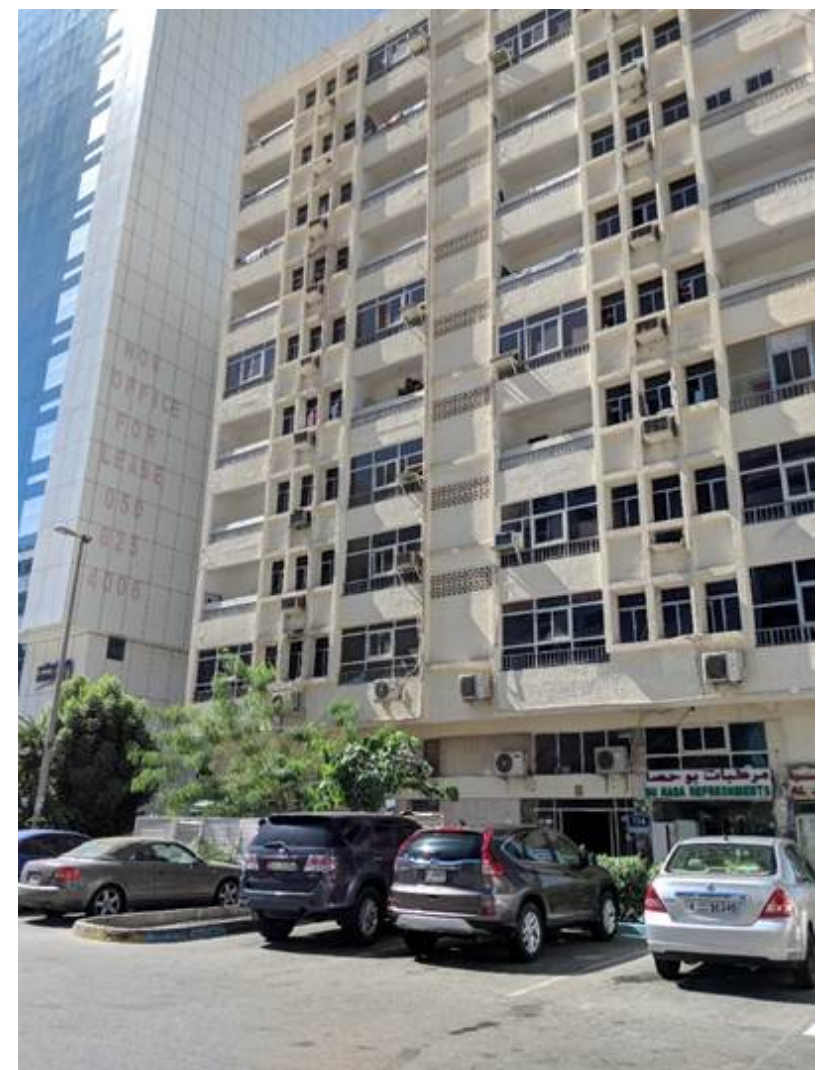

Figure 1 The case study area (Source: author).

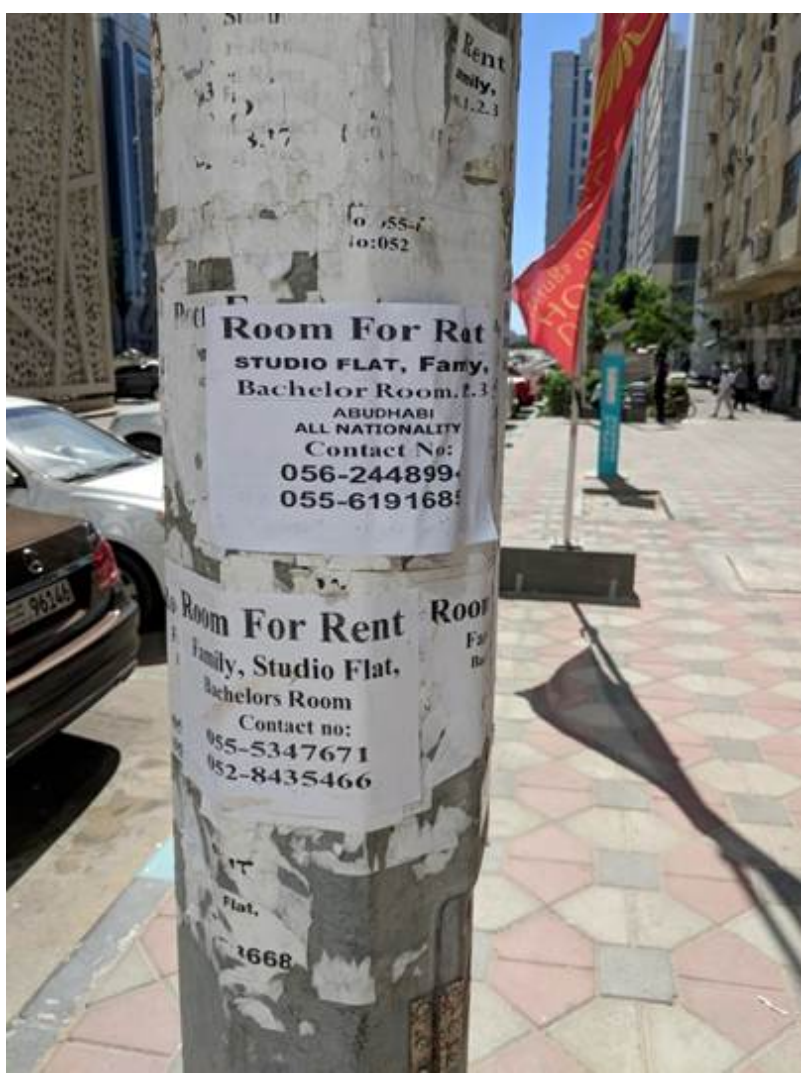

Figure 2 Informal housing arrangements. Workers appear socialising in the study area in the distance, whereas areas further away from the building are usually empty and lifeless (Source: author). 
The building houses a grocery store, a small restaurant and a bakery on one side, and a juice shop, a small library-supply store, and a second entrance for the grocery store. What makes this area noteworthy is that the space in front of the shops is vibrant and filled with young men relaxing and interacting casually while drinking tea or eating bread from the nearby bakery. In fact, around lunchtime and in the evenings, the area is usually full of workers.

Also notable in the space is the vegetation, as the residents and the shop attendants seem to maintain and plant vegetation in front of the building, contributing to the character of the space and providing shade for the social activities that take place there (Figures 3 and 4). This contrasts with other surrounding 'upgraded' streetscapes, which have no traces of vegetation or customisation by the residents. Oddly enough, the municipality has, and on multiple occasions, cut down the trees without notice in an apparent crackdown, only for them to be replaced or replanted by the users of the space.

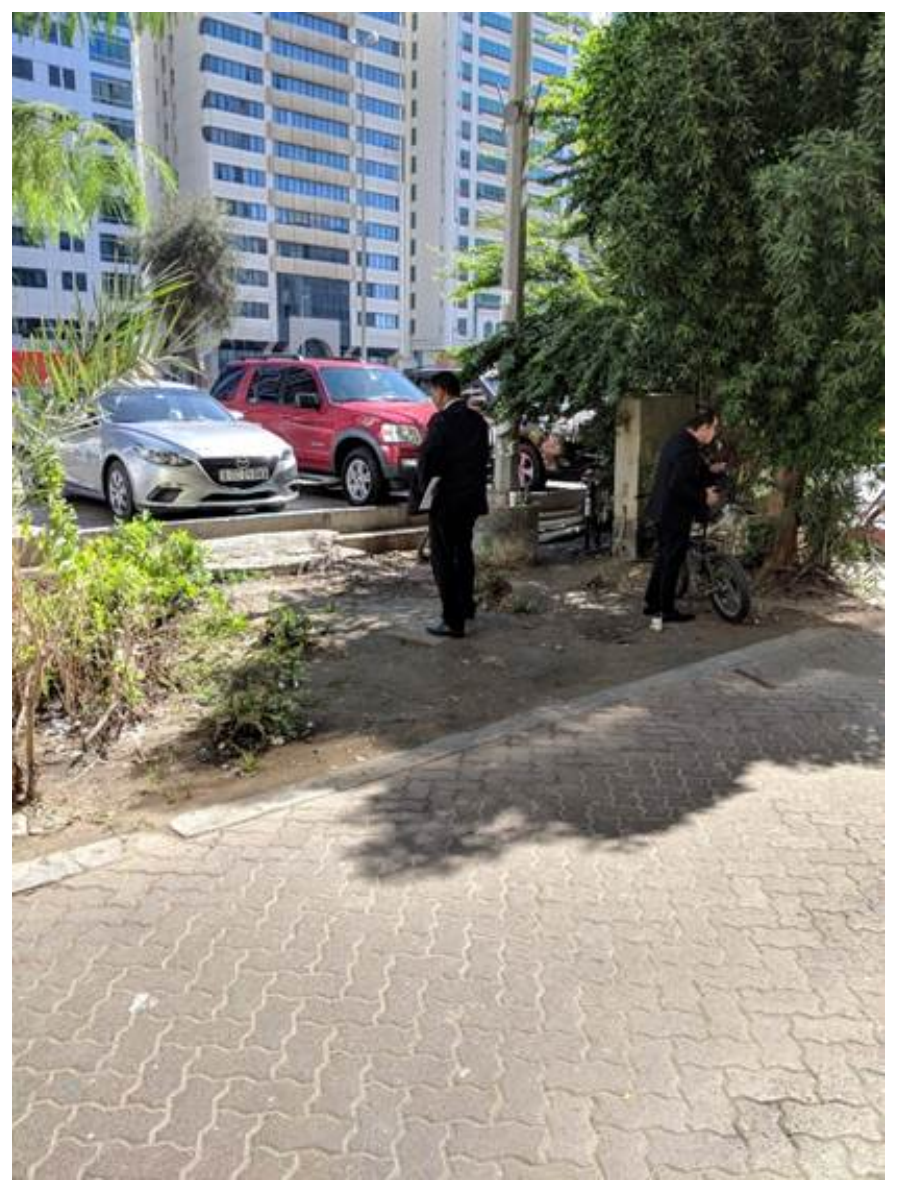

Figure 3 Enjoying a cup of tea and a cigarette in the shade after lunch (Source: author).

Finally, the transportation options for the residents of such a building are limited. The areas surrounding the building are packed with parked cars - a testament to the dominance of cars in the city's public space - but the building's residents and the space's users are not car owners, as it would be too expensive for them. Most of them walk, ride bicycles, or use delivery motorbikes provided by the employing company. Some would travel by taxi or public transport when needed. Figure 5 shows the parked motorcycles and some bicycles adjacent to the building in question. 


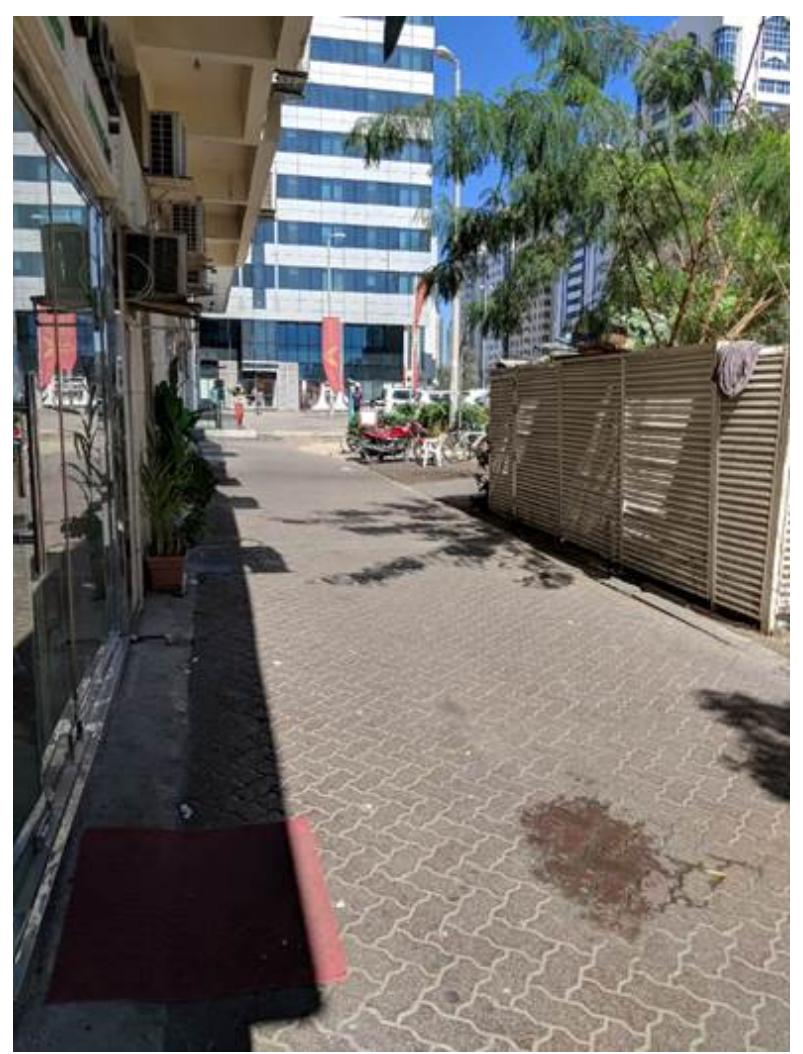

Figure 4 Users customise the public space, as is visible in the planters, the plants, the plastic chairs, and even the doormat. This is in contrast to the surrounding areas (Source: author).

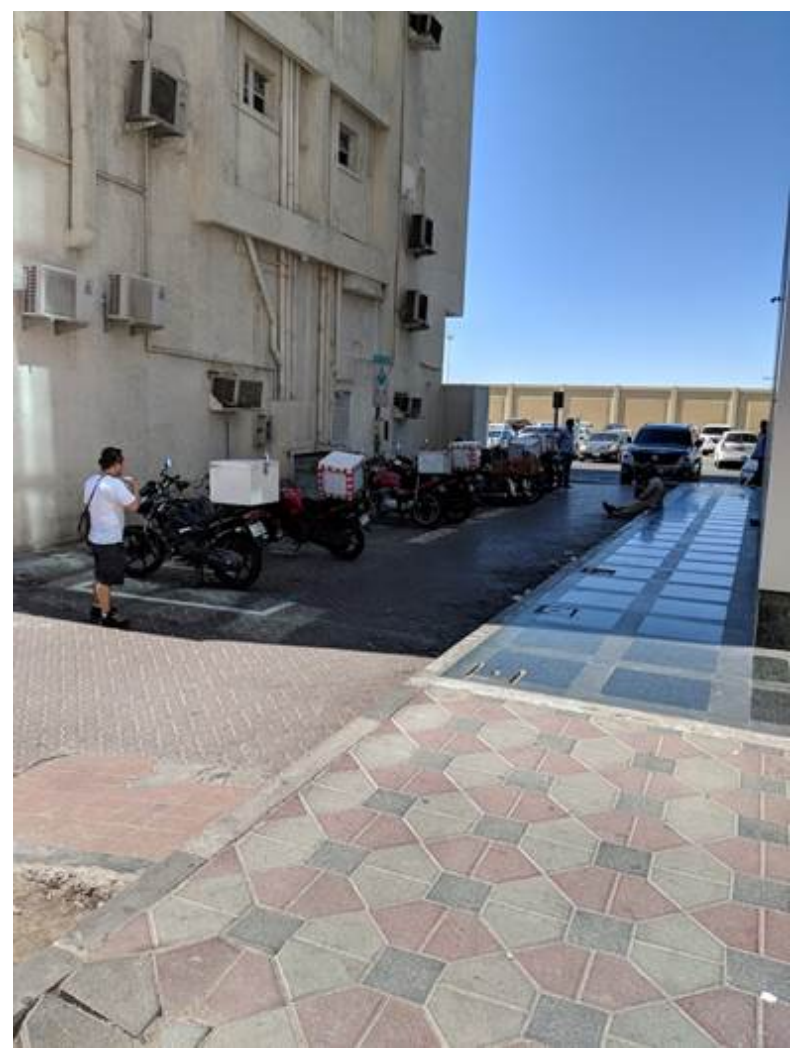

Figure 5 Delivery motorcycles and bicycles parked in the space. Most residents of the building and users of the space work in lower-paying jobs such as food delivery or as grocery store attendants (Source: author). 


\section{Discussion}

The urban space examined in this paper represents one of many similar informal urban spaces in Abu Dhabi. True to the literature, it gains its vibrancy from a multitude of elements, including social factors, economic activities, and design elements. These include street-level retail, a high population density supplied by the living arrangements in the building, and design features such as vegetation, shade, and movable chairs. All these ingredients help to create this vibrant area in an otherwise hot and arid environment. Still, the contrast between this informal space and the surrounding rather desolate and lifeless pavements is striking. This contrast appears to be the result of the different forces at play within the city, which are a by-product of its perceived high-end status and aspirations, its distinct demographics, and its society polarised along socio-economic lines. For instance, most of the planning efforts focus on newer affluent areas and do not focus on existing neighbourhoods. More importantly, the clear majority of the city's residents drive cars (or are driven) using their cars for even the shortest of journeys. Parking is a valuable commodity, always eroding public spaces and pavements - with policies to increase it even more. Most residents of the city appear to avoid the outdoors, especially during the warmer months, and want little to do with the outdoor spaces or its unwanted inhabitants. Finally, pavements are viewed as holding areas for infrastructure works, and not as a functional public space.

Therefore, it seems that for street life to emerge in Abu Dhabi, it needs a hint of informality and a population with limited income - to suppress car dependence. It might also be specific socio-cultural components, ethnic backgrounds, or a feeling of isolation and exclusion that help in fostering the need for such areas as documented in the literature on informality. ${ }^{31}$ One could argue that these spaces are glimpses into a parallel society of ethnically distinct, economically, and socially isolated individuals with their own set of problems beyond 'where can I park my car.' Nevertheless, the spaces are unique and vibrant and should be recognised and celebrated and not eliminated or pushed to the periphery. These informal spaces create some character in the city and generate a spontaneous street life. They also do not involve travelling to shopping malls in the suburbs or visiting expensive, secluded coffee shops with ample parking, which is typical in car-dominated lifestyles. The excluded populations that inhabit this space claim their right to city spaces, even if for a brief time - resembling a form of insurgent urbanism as described by Hou. ${ }^{32}$

\section{Conclusion: Worlds Apart and Lessons for Planning}

Abu Dhabi is a well-developed city with a high quality of life for most of its residents. It is unquestionably a city moving up in world city rankings, and its international appeal continues to grow with an emphasis on high-end living. Still, planners and city officials need to think outside the box and accommodate all segments of society. The urban space discussed in this paper provided an outlet and relief for an otherwise burdened population. It offered an energy absent from some of the formal planning efforts. It resulted from an informal housing solution to a complex housing problem. Finally, it represented a lifestyle without cars - a lifestyle where people walk, ride bicycles, and socialise in public spaces. By examining this case study as a representative of other similar informal urban spaces, this paper argues that there are lessons to be learned from these forgotten enclaves, including how to develop a functioning urban space, and how to generate street life. Planners in Abu Dhabi do not need to look far for best practices in urban design as solutions are present within the streets of the city - although they might have to look a bit harder!

More importantly, this paper hopes to advance the notion that world-class cities need not always be shiny, spotless, and monotonous. Some imperfections are normal and help add to the character and charm. True world-class cities are those that have more than shiny towers and signature developments. They are cities that have a bottom-up approach to planning. They cater to the needs of all their residents and help foster just, inclusive societies. Sustainable and resilient planning should include all segments of society, and ultimately attempt to advance the quality of life for all.

\section{Declarations and Conflict of Interests}

The author declares no conflict of interests with this work. 


\section{Notes}

${ }^{1}$ Boland, 'Sexing up the City'.

2 Rennie-Short, Global Metropolitan.

${ }^{3}$ Bagaeen, 'Brand Dubai'.

${ }^{4}$ Zaman, 'Louvre Abu Dhabi'.

${ }^{5}$ Elsheshtawy, Dubai.

${ }^{6}$ Sassen, 'The Global City'.

${ }^{7}$ Jacobs, Death and Life.

${ }^{8}$ Lynch, The Image of the City.

${ }^{9}$ Montgomery, 'Café Culture and the City'.

${ }^{10}$ Carmona, 'Contemporary Public Space'.

${ }^{11}$ Sheller and Urry, 'The City and the Car'.

${ }^{12}$ Loukaitou-Sideris and Ehrenfeucht, 'Vibrant Sidewalks in the United States'.

${ }^{13}$ Ehrenfeucht and Loukaitou-Sideris, 'Planning Urban Sidewalks'.

${ }^{14}$ Gehl, Life Between Buildings, 11.

${ }^{15}$ Abu Dhabi Urban Planning Council, Street Design Manual.

${ }^{16}$ Shahbandari, 'For Every Two Dubai Residents'.

${ }^{17}$ Sankar, 'Private Investors to Solve Parking Woes'.

${ }^{18}$ Qamhaieh and Chakravarty, 'Global Cities'.

${ }^{19}$ Mohammad and Sidaway, 'Shards and Stages'.

${ }^{20}$ Statistics Center of Abu Dhabi (SCAD), 'Statistical Yearbook'.

${ }^{21}$ Mohammad and Sidaway, 'Spectacular Urbanization'; Khalaf, 'Dubai Camel Market Transnational Workers'.

${ }^{22}$ Roy, 'Urban Informality'.

${ }^{23}$ Sims, 'The Arab Housing Paradox'.

${ }^{24}$ Elsheshtawy, 'Little Space, Big Space', 53.

25 Alawadi, 'Urban Redevelopment Trauma'.

${ }^{26}$ Elsheshtawy, 'Informal Encounters'.

${ }^{27}$ Leech, 'Life Between Malls and Apartment Blocks'.

${ }^{28}$ Chakravarty and Qamhaieh, 'City Upgraded'.

${ }^{29}$ Aghaddir, 'Sharjah Steps Up Inspections'.

${ }^{30}$ Hou, Insurgent Public Space.

${ }^{31}$ Elsheshtawy, 'Little Space, Big Space', 53.

${ }^{32}$ Hou, Insurgent Public Space.

\section{References}

Abu Dhabi Urban Planning Council. Street Design Manual (2010). Accessed June 28, 2018. https://nelsonnygaard.com/wp-content/uploads/2014/04/Abu-Dhabi-StreetDesignManual.pdf.

Aghaddir, Ali. 'Sharjah Steps Up Inspections of Illegal Bachelor Housing'. Gulf News, June 28, 2018. Accessed June 28, 2018. https://gulfnews.com/news/uae/government/sharjah-steps-up-inspectionsof-illegal-bachelor-housing-1.2071364.

Alawadi, Khaled. 'Urban Redevelopment Trauma: The Story of a Dubai Neighborhood'. Built Environment 40, no. 3 (2014): 357-75. [CrossRef]

Bagaeen, Samer. 'Brand Dubai: The Instant City; or the Instantly Recognizable City'. International Planning Studies 12, no. 2 (2007): 173-97. [CrossRef]

Boland, Philip. 'Sexing Up the City in the International Beauty Contest: The Performative Nature of Spatial Planning and the Fictive Spectacle of Place Branding'. Town Planning Review 84, no. 2 (2013): 251-74. [CrossRef]

Carmona, Matthew. 'Contemporary Public Space: Critique and Classification, Part One: Critique'. Journal of Urban Design 15, no. 1 (2010): 123-48. [CrossRef] 
Chakravarty, Surajit, and Abdellatif Qamhaieh. 'City Upgraded: Redesigning and Disciplining Downtown Abu Dhabi'. In Global Gentrifications: Uneven Development and Displacement, edited by Loretta Lees, Hyun Bang Shin and Ernesto López-Morales, 59-80. Bristol: Policy Press, 2015.

Ehrenfeucht, Renia, and Anastasia Loukaitou-Sideris. 'Planning Urban Sidewalks: Infrastructure, Daily Life and Destinations'. Journal of Urban Design 15, no. 4 (2010): 459-71. [CrossRef]

Elsheshtawy, Yasser. 'Cities of Sand and Fog: Abu Dhabi's Arrival on the Global Scene'. In The Evolving Arab City: Tradition, Modernity and Urban Development, edited by Yasser Elsheshtawy, 272-318. London: Routledge, 2008.

Elsheshtawy, Yasser. Dubai: Behind an Urban Spectacle. London: Routledge, 2009.

Elsheshtawy, Yasser. 'Little Space, Big Space: Everyday Urbanism in Dubai'. Brown Journal of World Affairs 17, no. 1 (2010): 53-71.

Elsheshtawy, Yasser. 'Informal Encounters: Mapping Abu Dhabi's Urban Public Spaces'. Built Environment 37, no. 1 (2011): 92-113. [CrossRef]

Gehl, Jan. Life between Buildings: Using Public Space. Washington, DC: Island Press, 2011.

Hou, Jeffrey, ed. Insurgent Public Space: Guerrilla Urbanism and the Remaking of Contemporary Cities. London: Routledge, 2010.

Jacobs, Jane. The Death and Life of Great American Cities. New York: Vintage, 1961.

Khalaf, Sulayman N. 'Dubai Camel Market Transnational Workers: An Ethnographic Portrait'. City \& Society 22, no. 1 (2010): 97-118.

Leech, Nick. 'Life Between Malls and Apartment Blocks: How Ordinary People Create Their Own City in Abu Dhabi'. The National, November 19, 2015. Accessed January 1, 2019. https://www.thenational.ae/arts-culture/life-between-malls-and-apartment-blocks-how-ordinarypeople-create-their-own-city-in-abu-dhabi-1.15942.

Loukaitou-Sideris, Anastasia, and Renia Ehrenfeucht. Sidewalks: Conflict and Negotiation over Public Space. Cambridge MA: MIT Press, 2009.

Loukaitou-Sideris, Anastasia, and Renia Ehrenfeucht. 'Vibrant Sidewalks in the United States: Re-Integrating Walking and a Quintessential Social Realm'. Access 26 (2010): 22-9.

Lynch, Kevin. The Image of the City. Cambridge MA: MIT Press, 1960.

Mohammad, Robina, and James D. Sidaway. 'Spectacular Urbanization amidst Variegated Geographies of Globalization: Learning from Abu Dhabi's Trajectory through the Lives of South Asian Men'. International Journal of Urban and Regional Research 36, no. 3 (2012): 606-27. [CrossRef]

Mohammad, Robina, and James D. Sidaway. 'Shards and Stages: Migrant Lives, Power, and Space Viewed from Doha, Qatar'. Annals of the American Association of Geographers 106, no. 6 (2016). [CrossRef]

Montgomery, John. 'Café Culture and the City: The Role of Pavement Cafés in Urban Public Social Life'. Journal of Urban Design 2, no. 1 (1997): 83-102. [CrossRef]

Qamhaieh, Abdellatif, and Surajit Chakravarty. 'Global Cities, Public Transportation, and Social Exclusion: A Study of the Bus System in Abu Dhabi'. Mobilities 12, no. 3 (2017): 462-78. [CrossRef]

Rennie-Short, John. Global Metropolitan: Globalizing Cities in a Capitalist World. London: Routledge, 2013.

Roy, Ananya. 'Urban Informality: Toward an Epistemology of Planning'. Journal of the American Planning Association 71, no. 2 (2005): 147-58. [CrossRef]

Sankar, Anjana. 'Private Investors to Solve Parking Woes of Abu Dhabi'. Khaleej Times, January 25, 2017. Accessed June 28, 2018. https://www.khaleejtimes.com/private-investors-to-solve-parking-woes-ofabu-dhabi.

Sassen, Saskia. The Global City. New York: Princeton University Press, 2001.

Shahbandari, Shafaat. 'For Every Two Dubai Residents, There is One Car: Vehicle Density in the City Exceeds Some of the World's Biggest Metropolises'. Gulf News, March 15, 2015. Accessed December 1, 2018. https://m.gulfnews.com/news/uae/for-every-two-dubai-residents-there-is-onecar-1.1472177.

Sheller, Mimi, and John Urry. 'The City and the Car'. International Journal of Urban and Regional Research 24, no. 4 (2000): 737-57. [CrossRef] 
Sims, David. 'The Arab Housing Paradox'. The Cairo Review of Global Affairs 11, fall (2013): 38-42.

Statistics Center of Abu Dhabi (SCAD). Statistical Yearbook - Labour Force Structure 2017. Accessed June 28, 2018. https://www.scad.ae/Release\%20Documents/Statistical\%20Yearbook\%20\%20Labour\%20Force\%20Structure\%20-\%20EN.pdf.

Zaman, Samihah. 'Louvre Abu Dhabi Opens to Public'. Gulf News, November 11, 2017. Accessed June 28, 2018. https://gulfnews.com/news/uae/culture/louvre-abu-dhabi-opens-to-public-1.2122318. 